Vol. 11, No. 41, October, 2016, 1327-1340

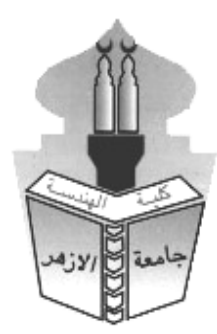

\title{
DESIGN OF ENERGY-EFFICIENT BUILDINGS IN CLEAR SKY CONDITIONS TO ENHANCE NATURAL LIGHTING THROUGH MAXIMIZING THE EXTERNAL REFLECTED COMPONENT
}

\author{
A. M. Saleh \\ Professional Engineer (Private Sector)

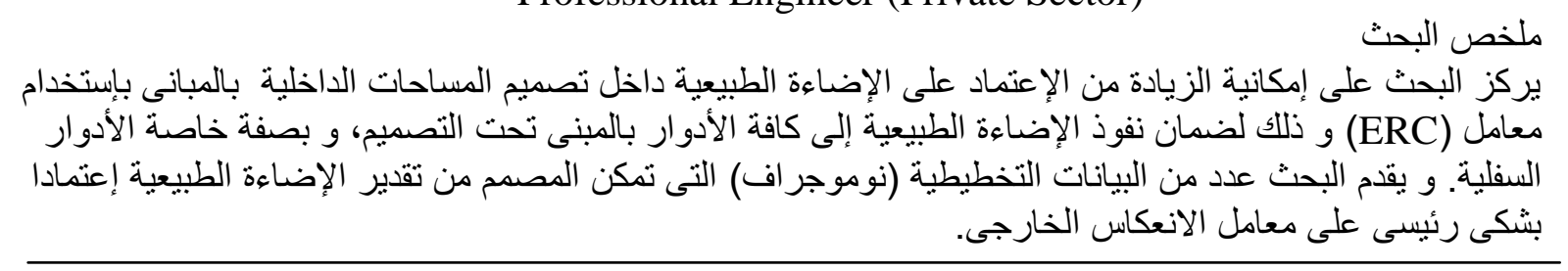

\section{ABSTRACT}

The importance of natural lighting cannot be overstated, especially when one considers the numerous health benefits and performance enhancements associated with those working or dwelling in well-lit spaces relying predominantly on daylight. Natural lighting, or daylighting, had been the subject of many previous research papers, but with emphasis on the Sky Component (SC) and the Internal Reflected Component (IRC), as the main contributing factors to the total luminance levels inside a given interior space.

The third component; External Reflected Component (ERC) had been neglected by most researchers, architects, engineers and scientists, possibly because of its smaller weight in comparison with the other components.

In today's age of high-rise towers and dense urban societies where the number of floors in a given building often reaches the order of 20's or 30's, bottom floor levels that are obstructed from natural lighting due to the surrounding tall structures, require further studies. In such cases, where the accessibility to natural lighting from the SC and IRC factors is small, it is important to find ways to maximize the capture and use of the ERC reflected from opposite buildings. This is the core subject of this Research which aims at providing a full analysis of ERC and how it changes with varying parameters which in turn provides a much-needed better understanding of how it performs under varying conditions, especially under clear skies.

Computer simulations will be carried out in sequence and results will be recorded and analyzed to find trends and establish logical patterns of how ERC changes. The study will then provide an analysis of the Egyptian Building Code to determine whether daylighting was considered in its numerous equations and stipulations that regulate development and construction activities. This includes maximum building height requirements, fenestration design and dimensions, and internal lighting-service channels in urban settings.

Key Words: Energy Conservation, External Reflected Component, ERC

\section{SUMMARY AND AIM OF WORK}

The majority of tools available today for the designer to increase natural lighting in an interior space are primarily concerned with only the Sky Component (SC) and the Internal Reflected Component (IRC), with little emphasis directed to the External Reflected Component (ERC). This is despite the fact that the (ERC) can have a significant weight under clear sky conditions that are prevalent in the Middle East and Africa in addition to other sunny zones such as South Amaerica. 
The aim of this work is to investigate ways to predict the (ERC) in order to enhance natural illumination, especially in cases where a subject building is located in a highly-dense population area such as those commonly found in emerging economies and Arabian gulf. For example, interior spaces are often subjected to a specific amount of illumination from the sky component (SC) due to an inherent pre-existing sky angle which makes it necessary to capitalize on other components of daylight. Also, the occupants of an interior space may choose certain interior wall colors based on personal preference, thereby affecting the internal reflected component (IRC). These cases warrant more research to study the ERC, which is the only component in the hands of the designer that can be controlled by tailoring urban development regulations to promote natural lighting.

This paper will present the experimental procedure undertaken through the researcher via computer simulations, and shall present parameters, findings and proposals for the designer to be able to make more informed decisions by relying primarily on ERC as one of the sources for daylight with enhancements from other components such as IRC.

\section{Parameters}

\subsection{Fixed Parameters}

- Floor Height: 3 meters

- Number of Floors: 12

- Total Building Height: 36 meters

- Location: Cairo, Egypt

\subsection{Variable Parameters Under Study}

- External facade colors of opposite Tower

- Dark Grey (10\% Reflectivity)

- Grey (30\% Reflectivity)

- Light Grey (70\% Reflectivity)

$\circ \quad$ White (90\% Reflectivity)

- Window to Floor Ratios
- $5 \%$ (0.5 square meters) Not code-compliant but performed only for research
- $10 \%$ (1 square meters)
- $16.7 \%$ (1.5 square meters)
- $22 \%$ (2 square meters)
- $\quad 33 \%$ (3 square meters)
- $67 \%$ (9 square meters)

- Fronting Road Widths
- 4 meters wide (Not code-compliant but performed only for research)
- 6 meters wide (Not code-compliant but performed only for research)
- 12 meters wide
- 24 meters wide
- 48 meters wide

- Floor Levels

$\begin{array}{ll}\circ & \text { 1st Floor } \\ \circ & \text { 2nd Floor } \\ \circ & \text { 3rd Floor } \\ \circ & \text { 4th Floor } \\ \circ & \text { 5th Floor } \\ \circ & \text { 6th Floor } \\ \circ & \text { 12th Floor } \\ \text { Building Orientations } \\ \circ & \text { North } \\ \circ & \text { East } \\ \circ & \text { South } \\ \circ & \text { West }\end{array}$


DESIGN OF ENERGY-EFFICIENT BUILDINGS IN CLEAR SKY CONDITIONS TO ENHANCE NATURAL LIGHTING THROUGH MAXIMIZING THE EXTERNAL REFLECTED COMPONENT

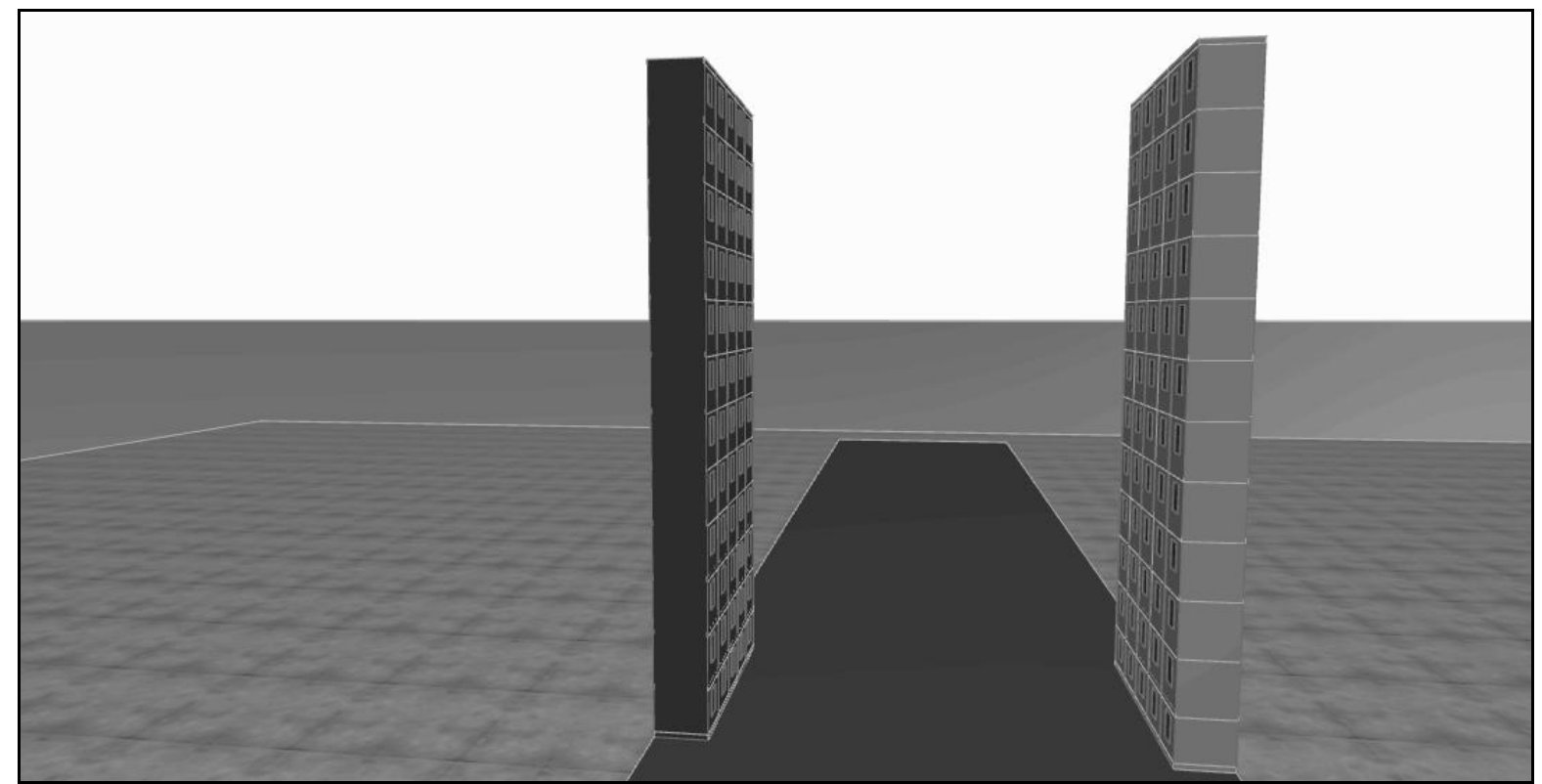

Fig.1 Three Dimensional Model showing opposite towers (36 meter Height)

- Simulation Times
- 9:00 AM
- 12:00 PM
- 3:00 PM

- Simulation Dates
- 21st June
- 21st December

4. Behavior of ERC

\subsection{Seasonal Variance}

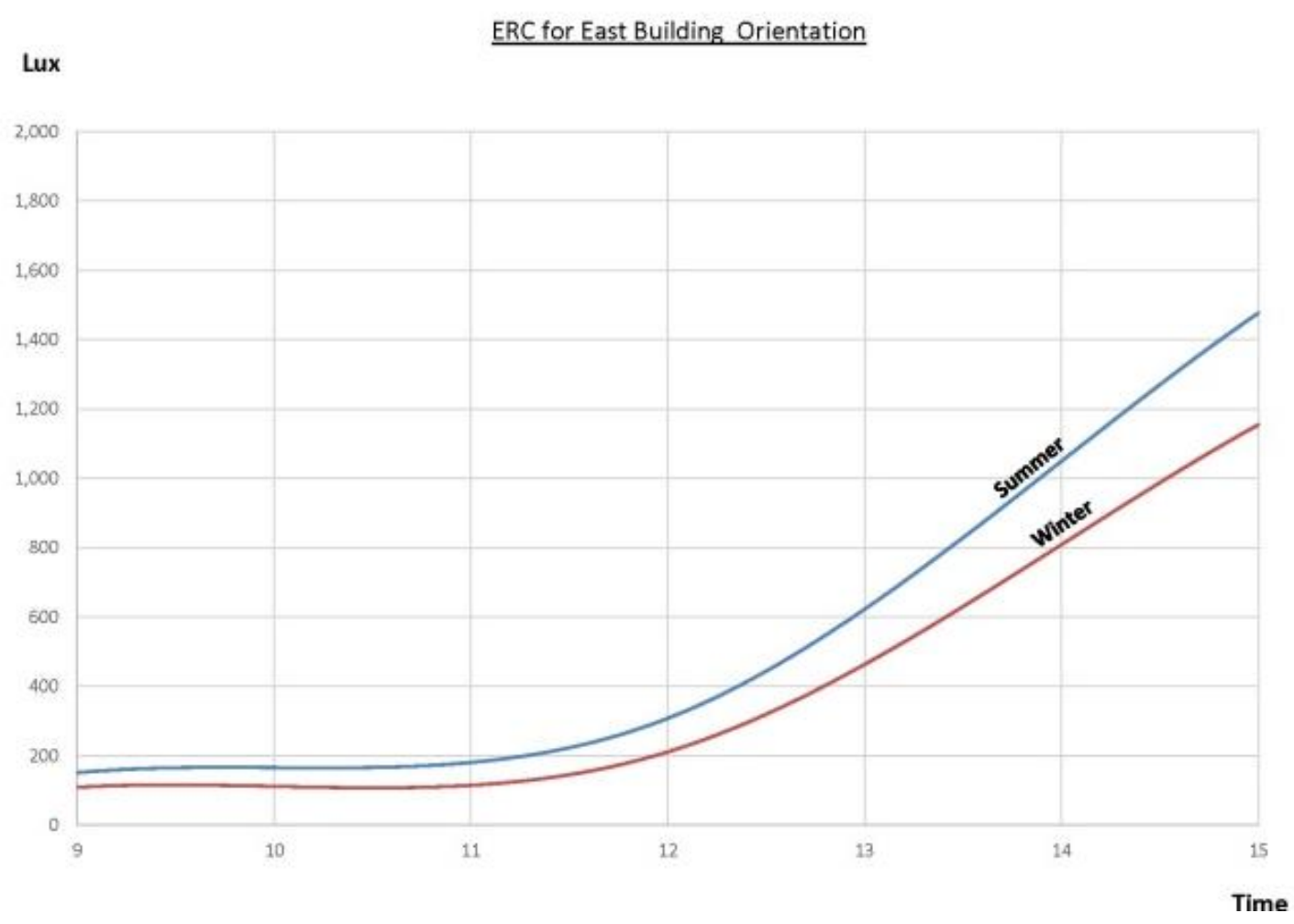

Fig. 2 (East Orientation) 
DESIGN OF ENERGY-EFFICIENT BUILDINGS IN CLEAR SKY CONDITIONS TO ENHANCE NATURAL LIGHTING THROUGH MAXIMIZING THE EXTERNAL REFLECTED COMPONENT

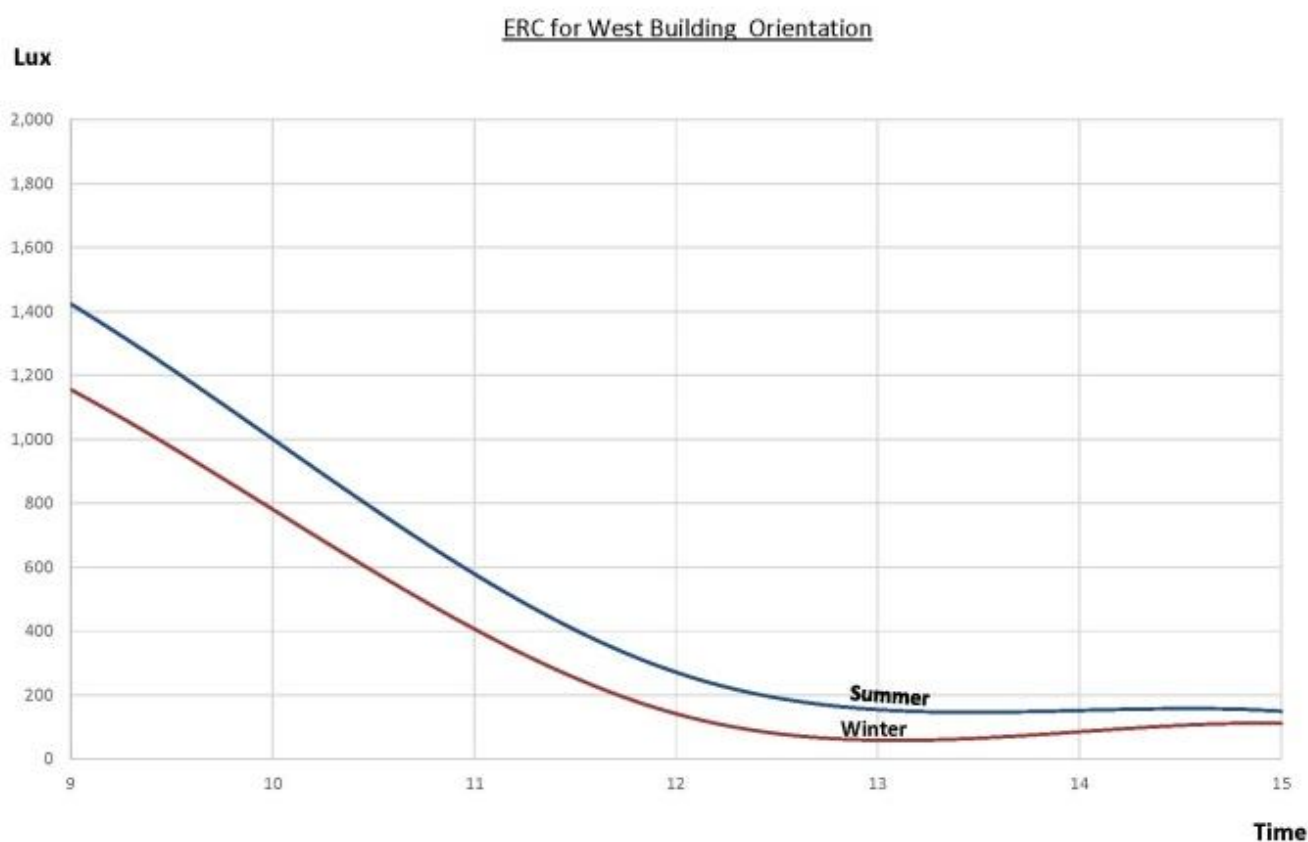

Fig. 3 (West Orientation)

Time

Lux

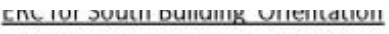

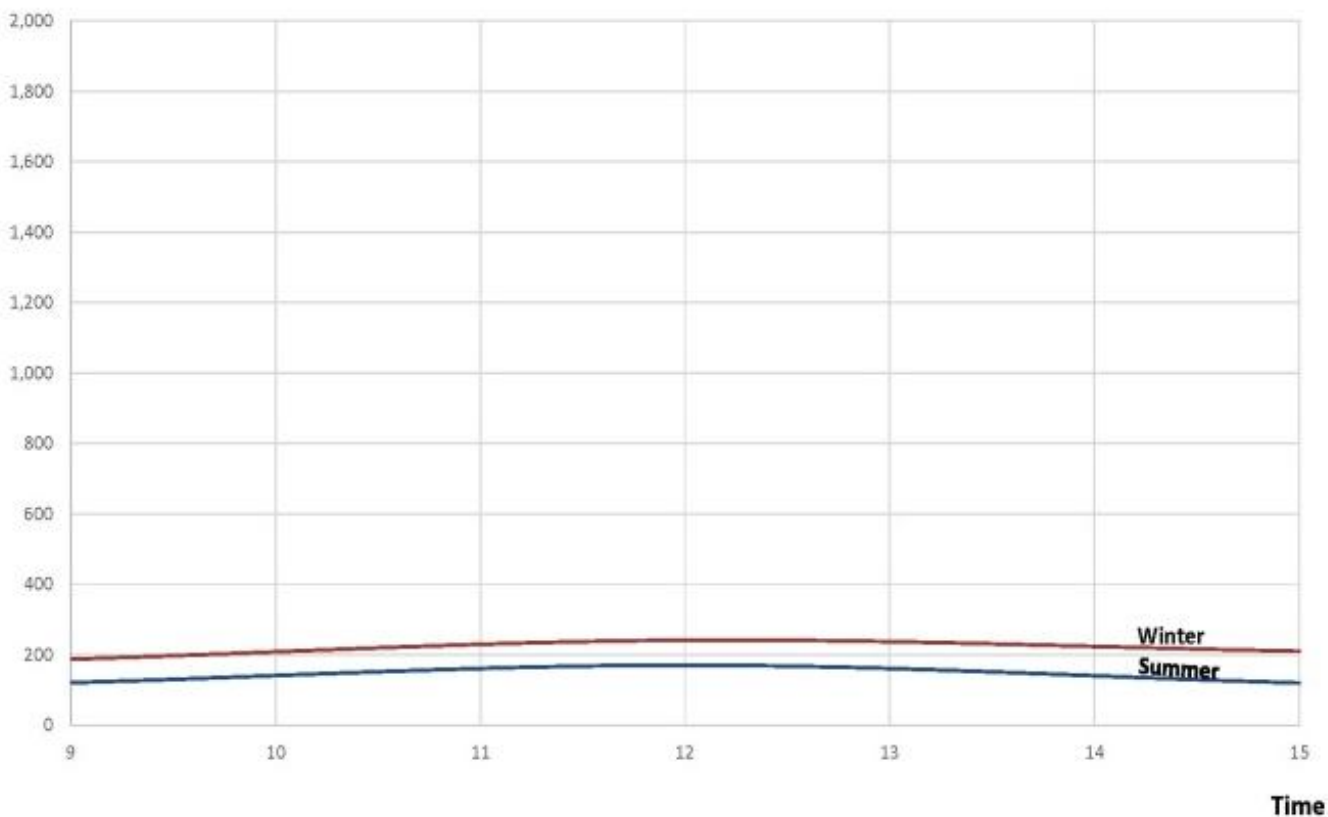

Fig. 4 (South Orientation) 


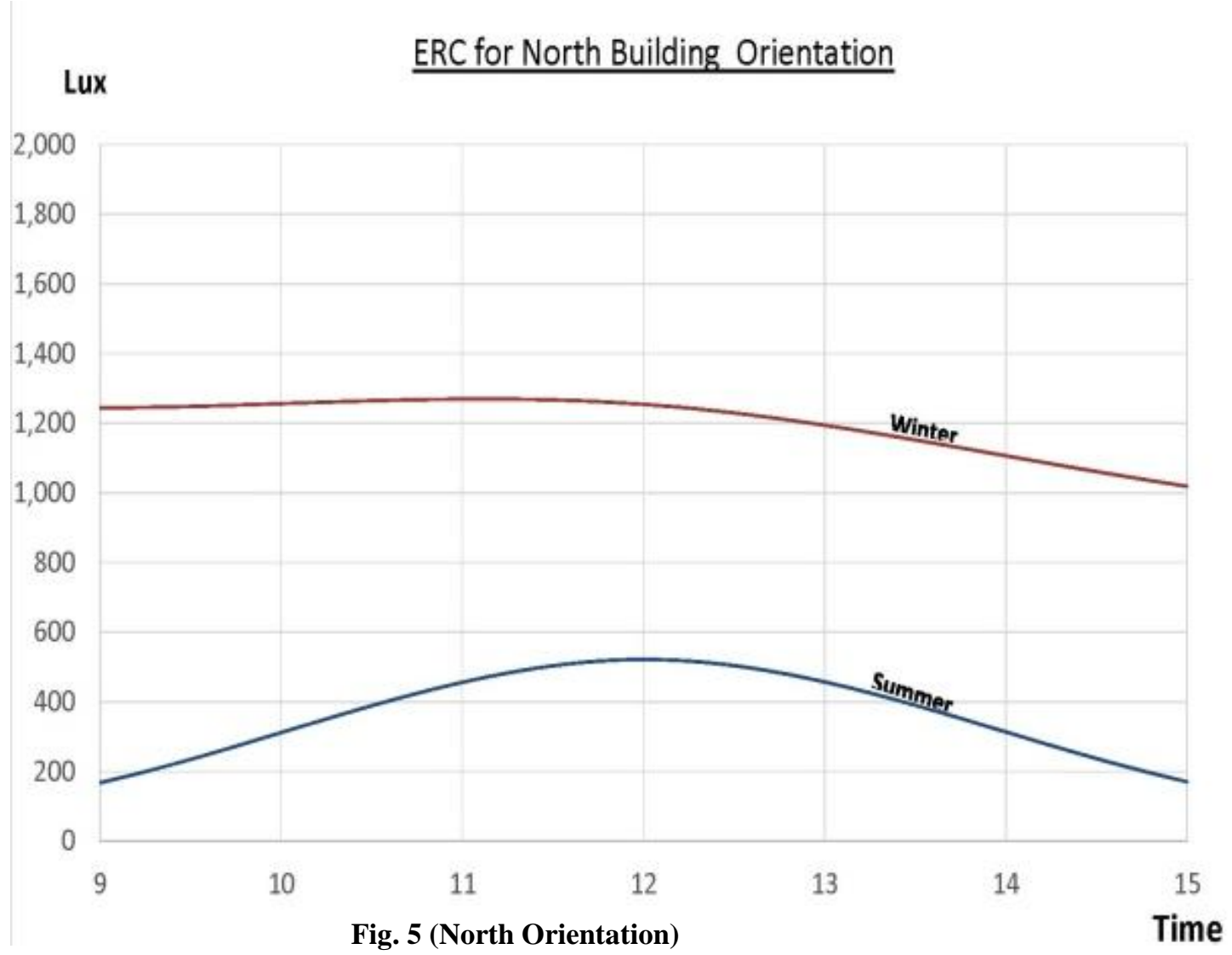

From the above charts, at 9:00 AM the Western orientation receives light from the opposite façade which is facing the Eastern orientation which is the reason for the high ERC value at 9:00 AM, decreasing to stabilize and diminish at around 12:00 PM.

As for the Eastern orientation, the Western façade is the source of ERC light starting from 12:00 PM onwards.

The cause for the variance between Winter and summer seasons in the Northern façade is due to the sunpath for the Cairo, Egypt location (30 Degrees North - 31 Degrees East) as seen from the diagram below where the sun is low in the horizon.

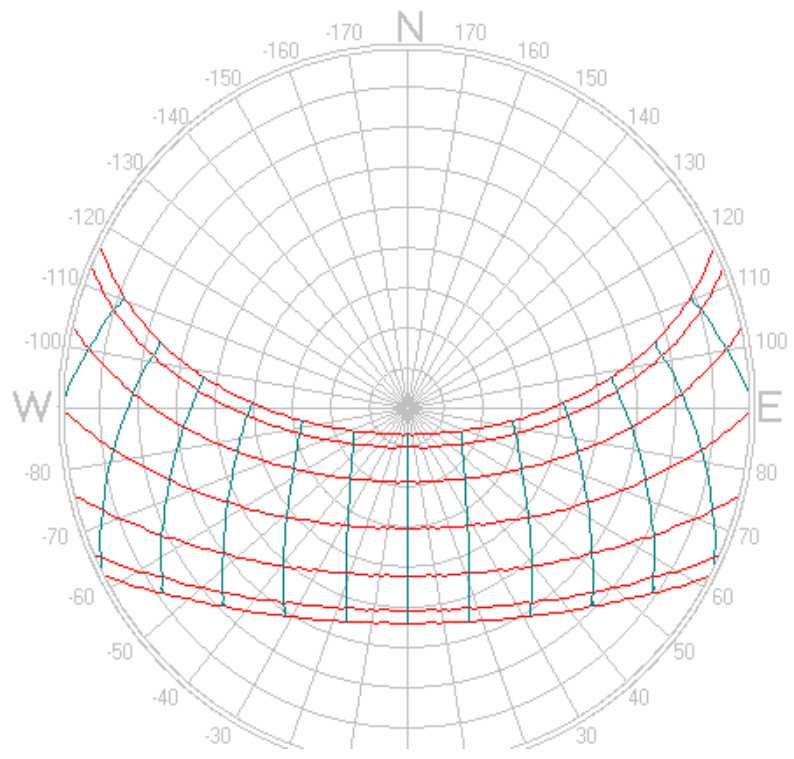

Fig. 6 - Sun Path Diagram for 30 Degrees North - 31 Degrees East 


\section{$\underline{4.2 \text { Road Widths }}$}

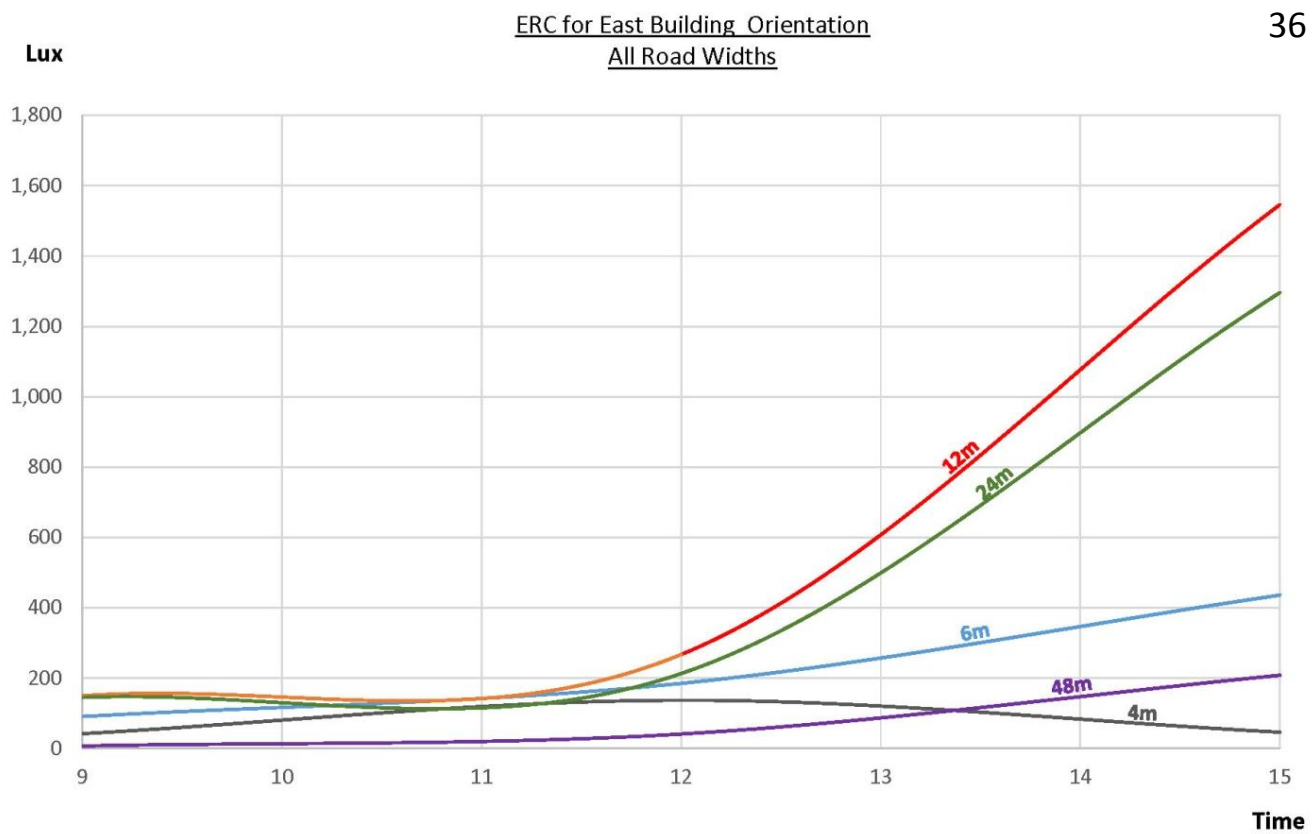

Fig. 7 - ERC Behavior (East Orientation) at Different Road Widths

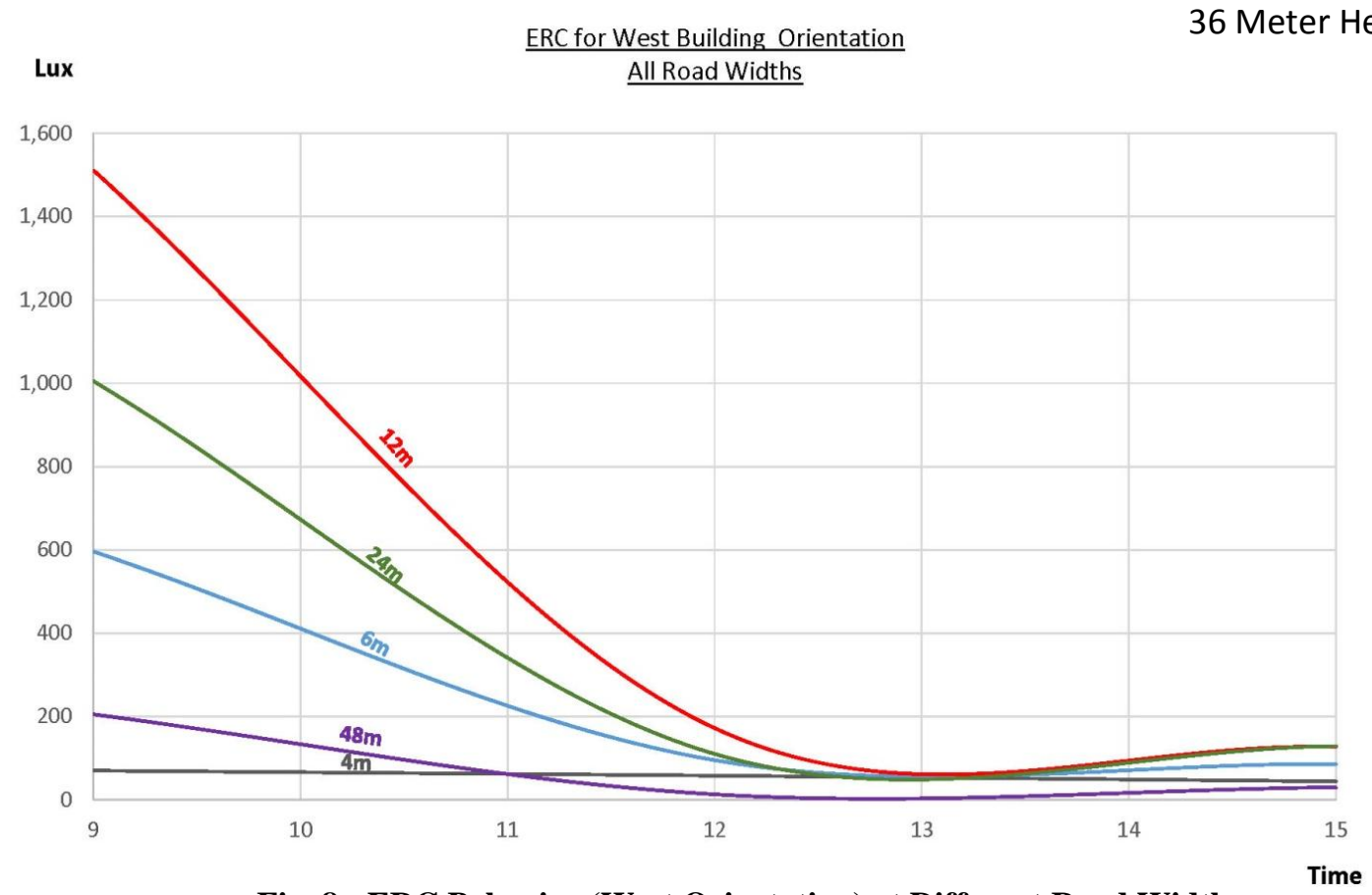

Fig. 8 - ERC Behavior (West Orientation) at Different Road Widths

From the above two charts, it is clear that the ERC for East and West orientations follow opposite patterns. It can also be deduced that all the ideal road width is 12 meters from the perspective of the ERC component. 
DESIGN OF ENERGY-EFFICIENT BUILDINGS IN CLEAR SKY CONDITIONS TO ENHANCE NATURAL LIGHTING THROUGH MAXIMIZING THE EXTERNAL REFLECTED COMPONENT

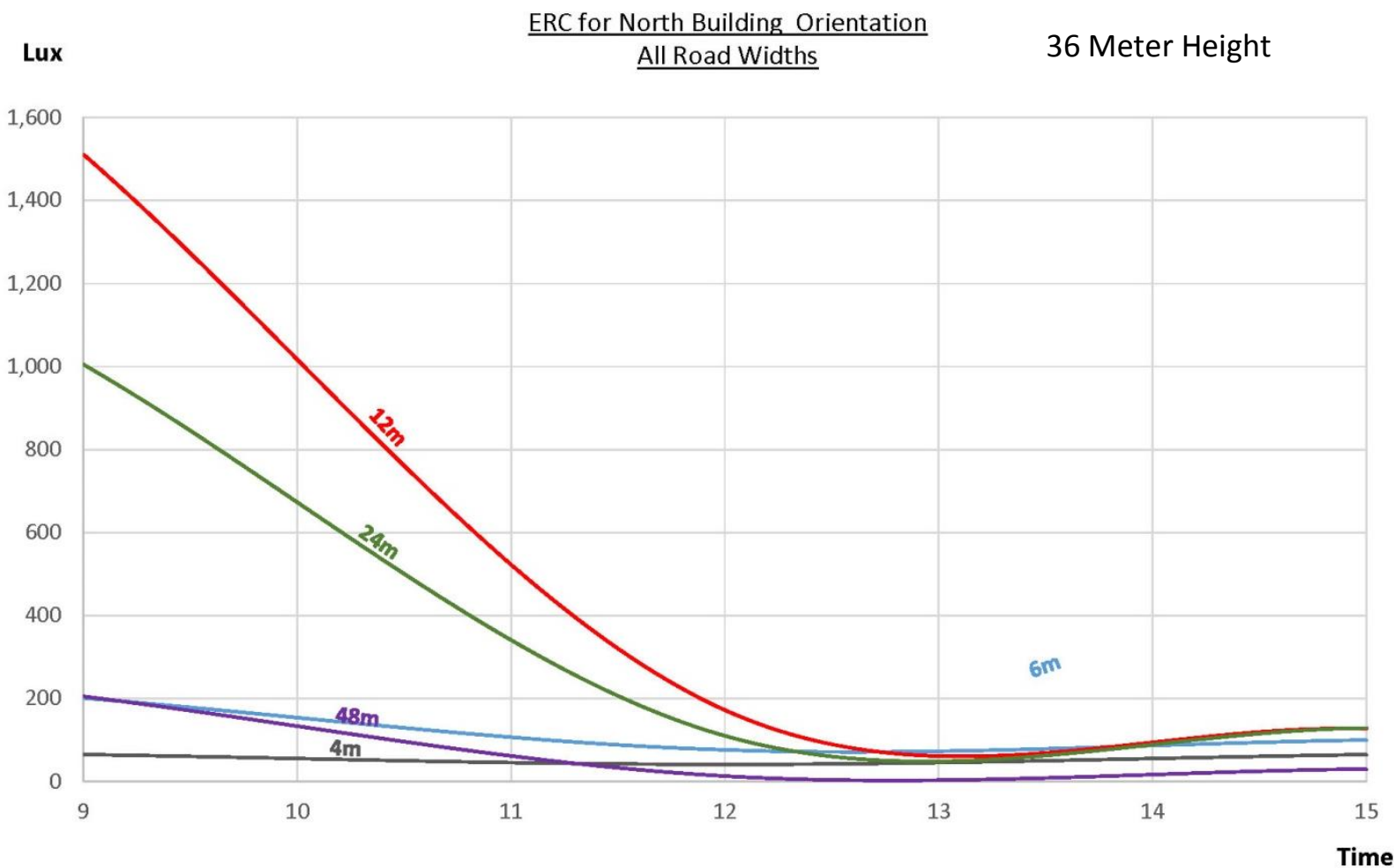

Fig. 9 - ERC Behavior (North Orientation) at Different Road Widths

Lux

All Road Widths

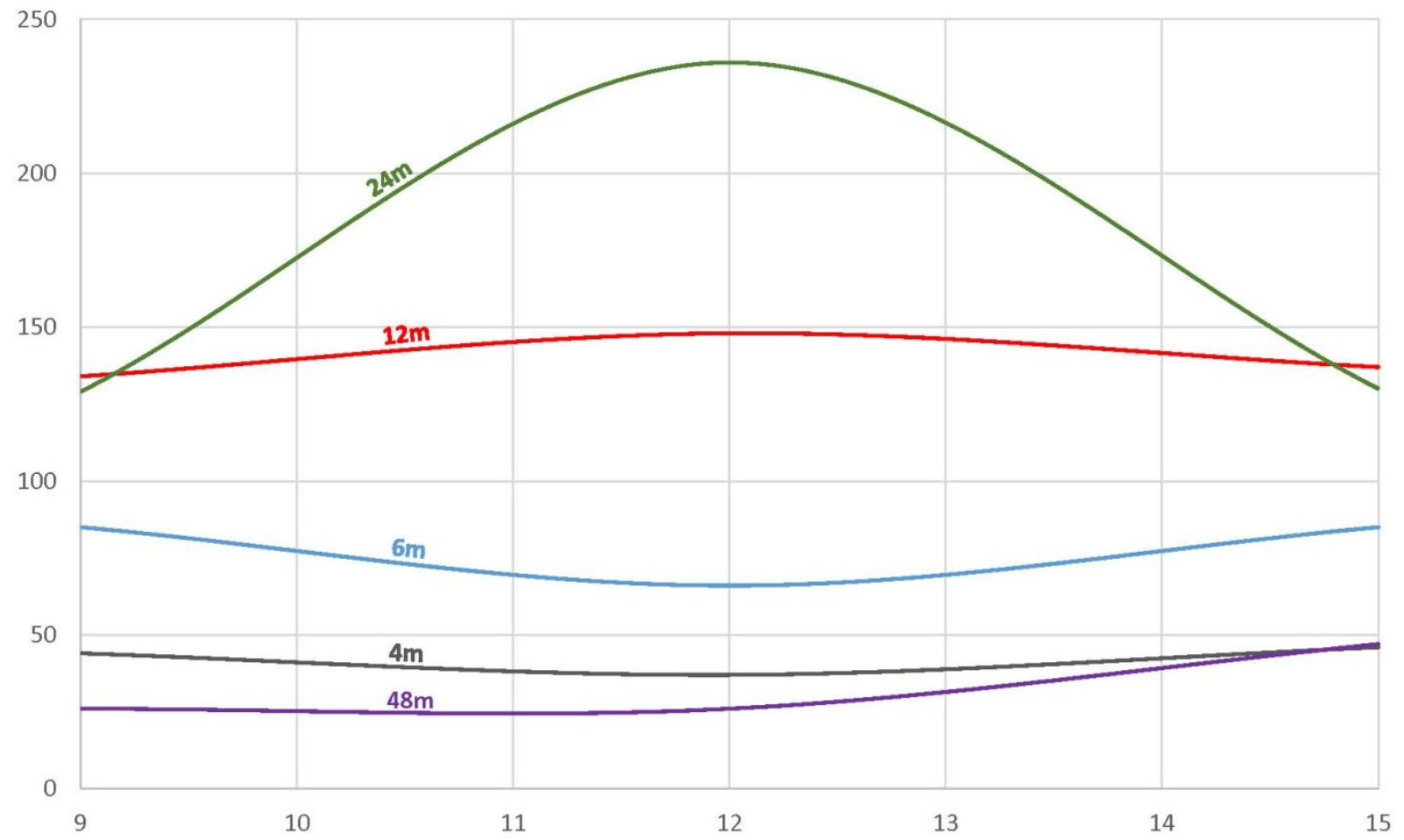

Fig. 10 - ERC Behavior (South Orientation) at Different Road Widths 
The South Orientation receives very low ERC value as can be seen from the scale which reflects a peak of 240 Lux at the 24 meter road width. It is therefore not practical to rely on the ERC to satisfy daylighting requirements if the interior space under design is in this direction.

\subsection{Color of Façade Reflecting Sunlight}

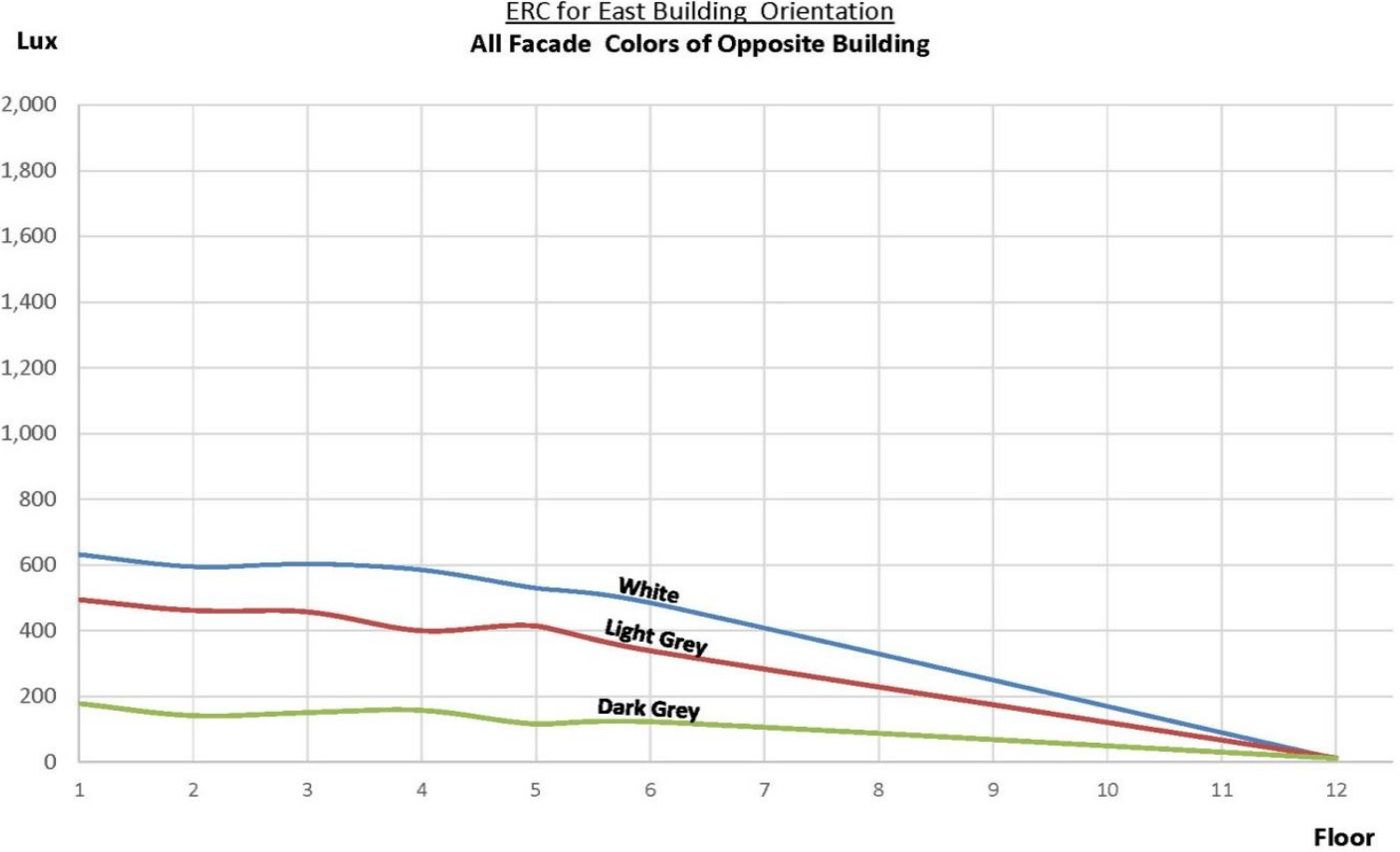

Fig. 11 - ERC Behavior (East Orientation) at Different Façade Colors

Lux

2,000

1,800

1,600

1,400

1,200

1,000

800

600

400

200

0

ERC for West Building Orientation

All Facade Colors of Opposite Building

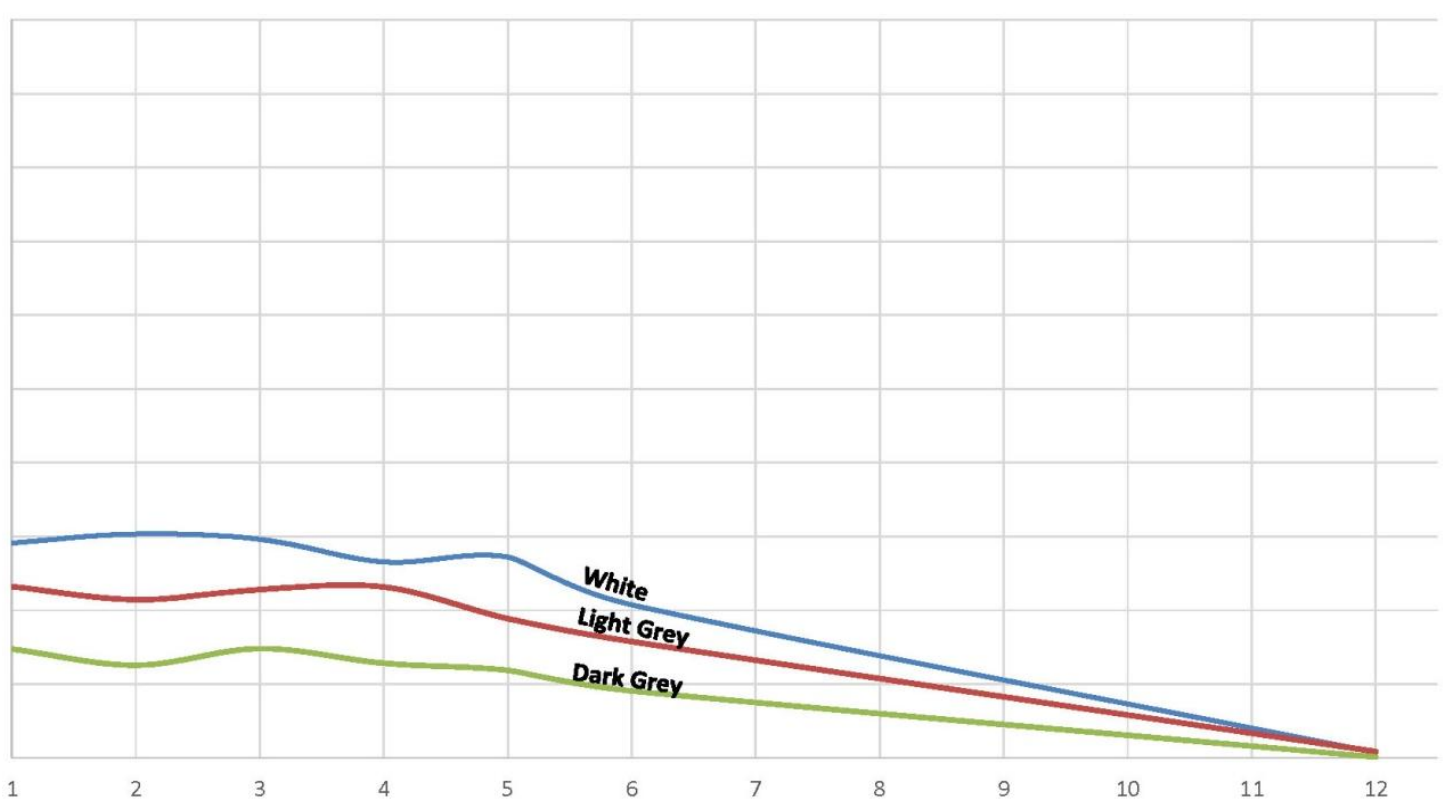

Floor

Fig. 12 - ERC Behavior (West Orientation) at Different Façade Colors 


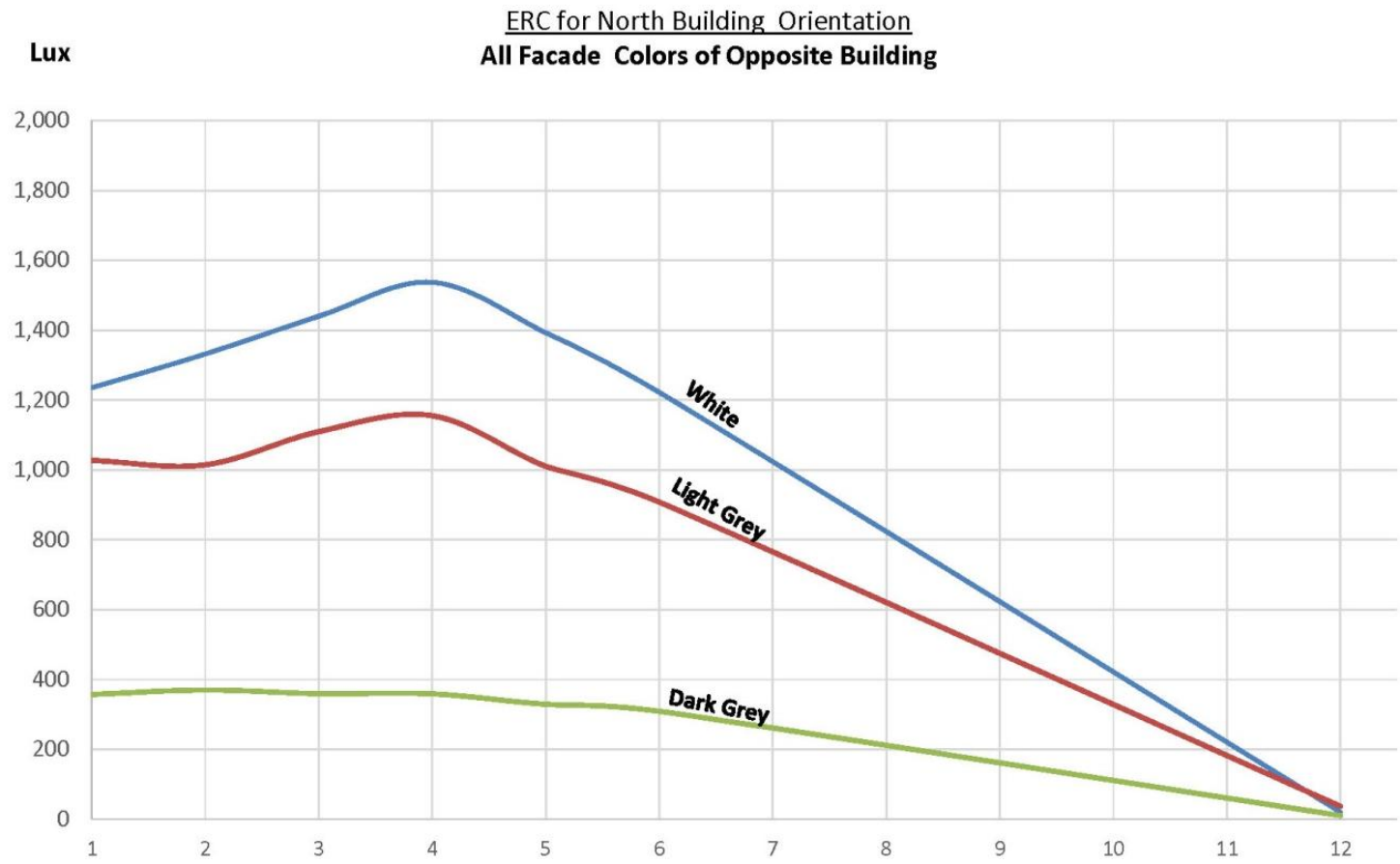

Fig. 13 - ERC Behavior (North Orientation) at Different Façade Colors $\quad$ Floor

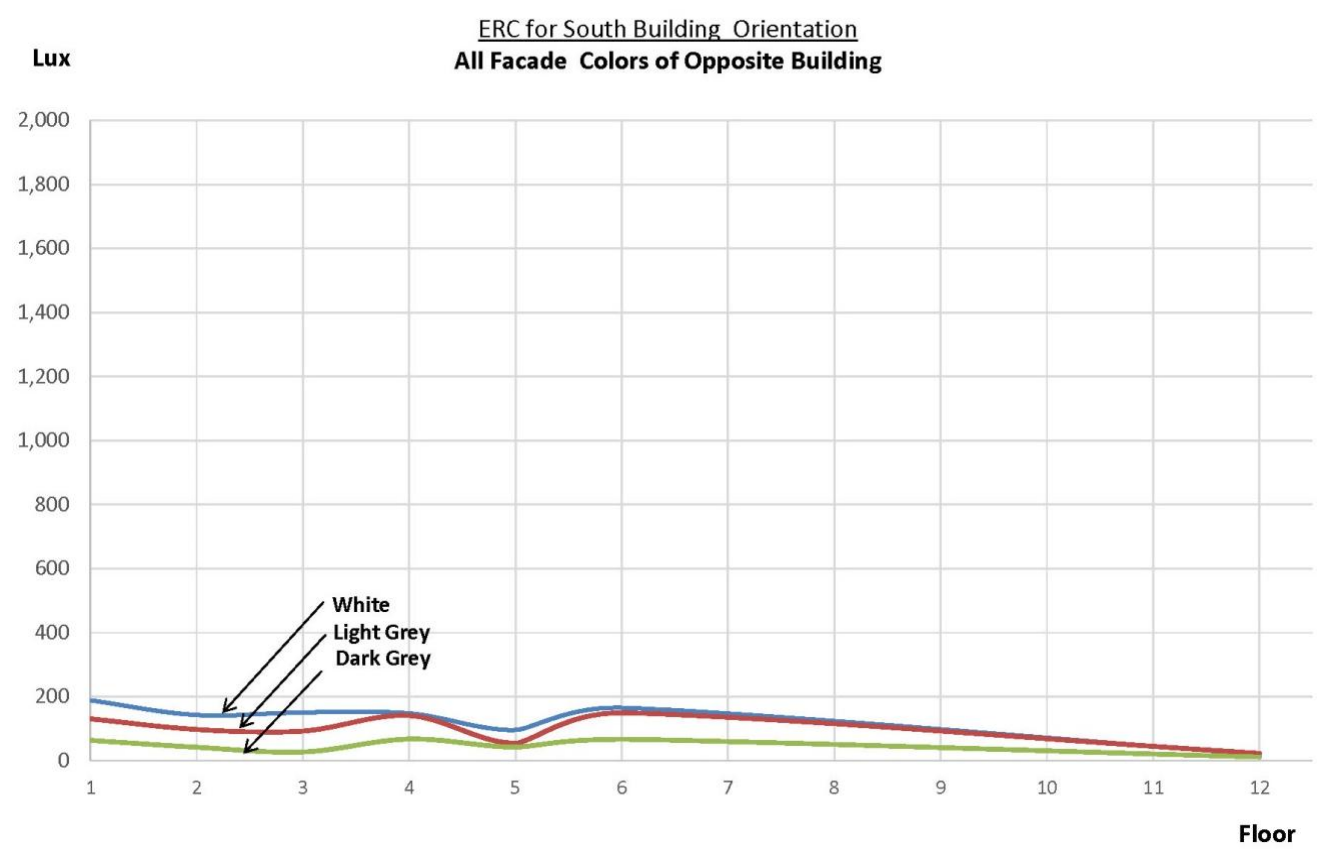

Fig. 14 - ERC Behavior (South Orientation) at Different Façade Colors

From the above charts, it is clear using a white reflective color of the opposite building would be a wise design decision to be taken by the urban planner if the intent is to maximize the 'reliance on the ERC reaching interior space. It is also evident that the ERC can be sufficient for general tasks and light reading for al orientations during most of the daytime. However, the South façade will require additional measures to be undertaken to enhance the daylight illumination levels.

\section{THE PROPOSED DESIGN CHARTS}


Presented below are 4 Nomograms that are the combination of all simulation results which can be used by the designer in order to predict the approximate value of ERC and make design decisions accordingly.

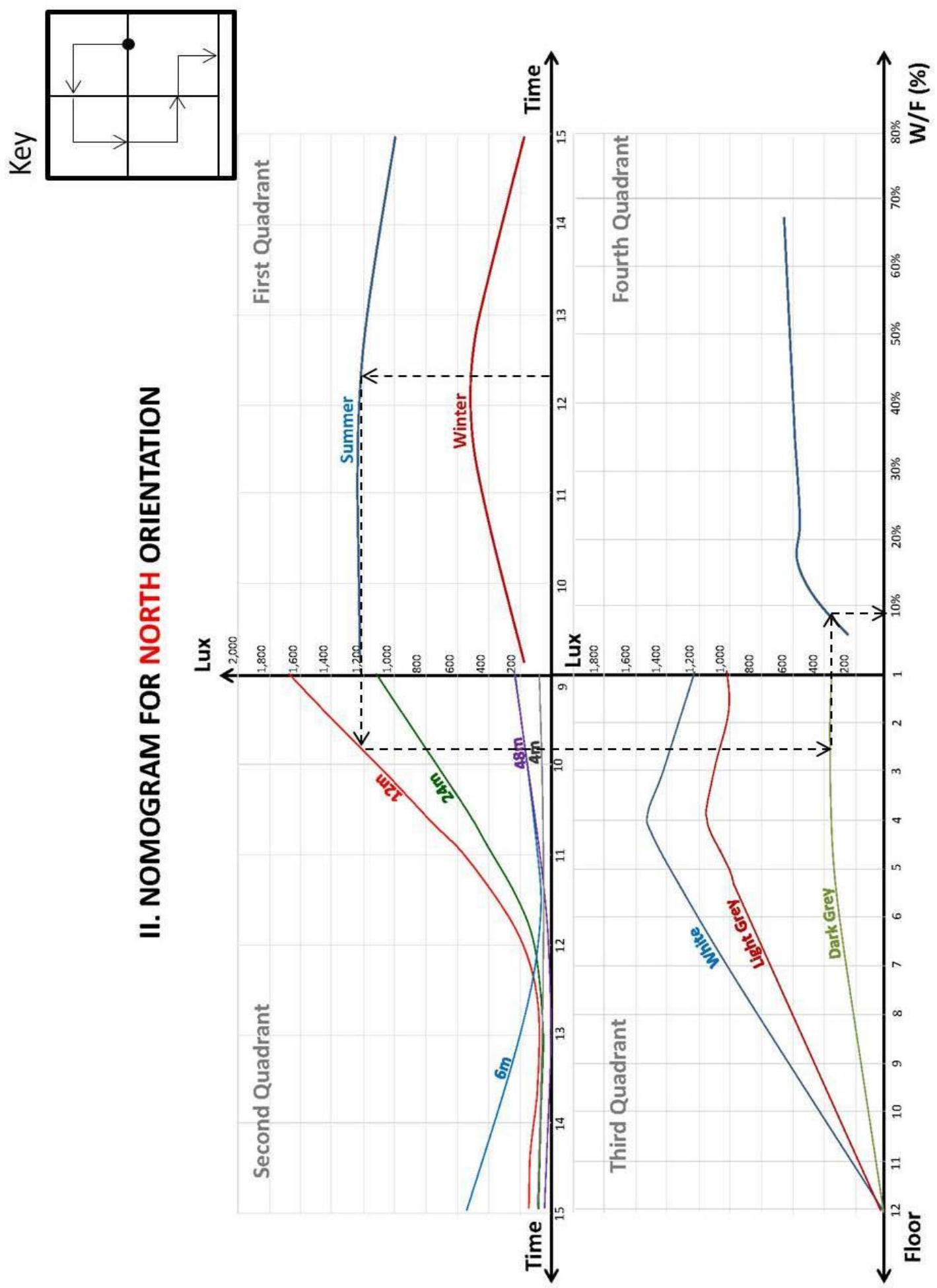

Fig. 15 - North Orientation Nomogram 


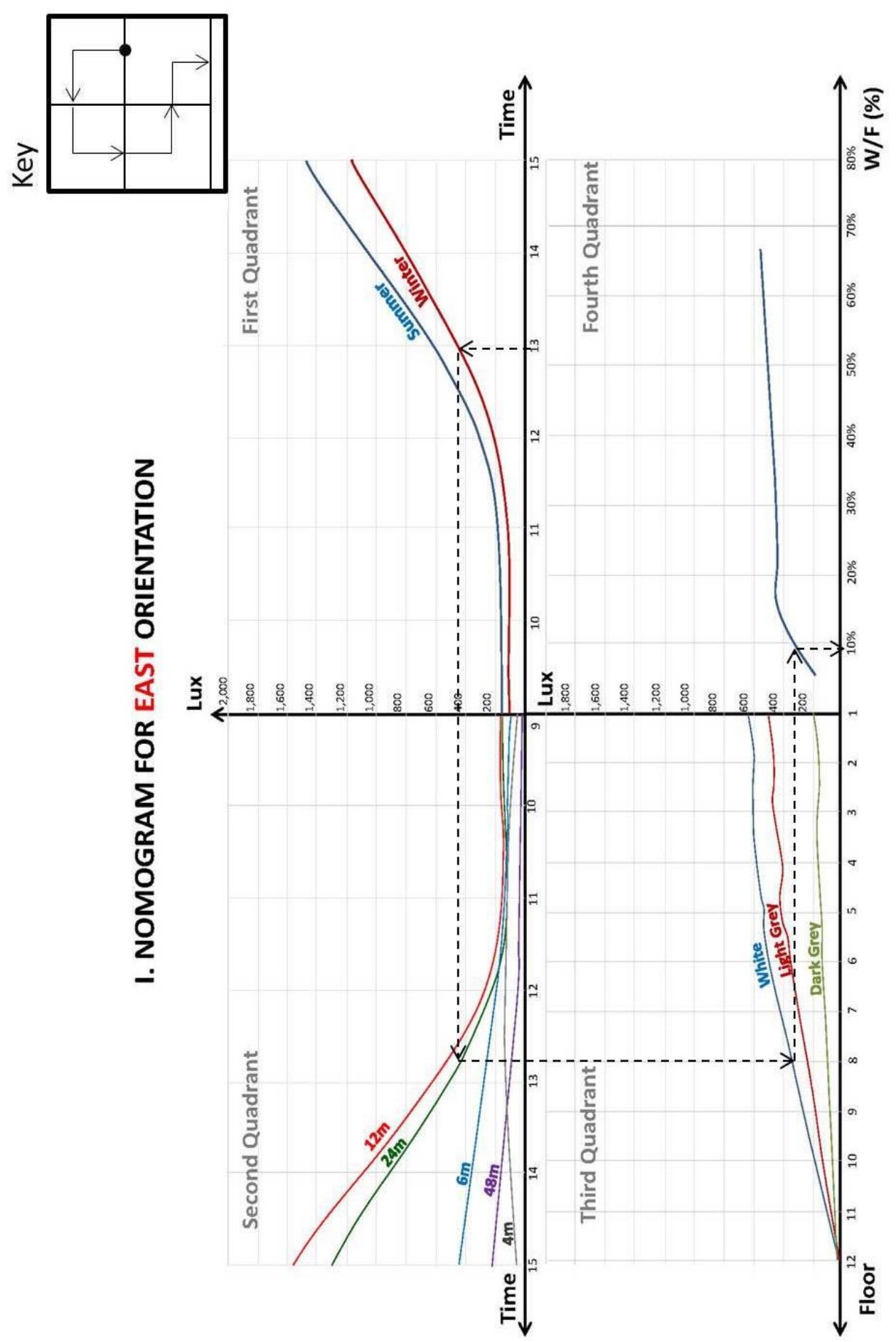

Fig. 16 - East Orientation Nomogram 


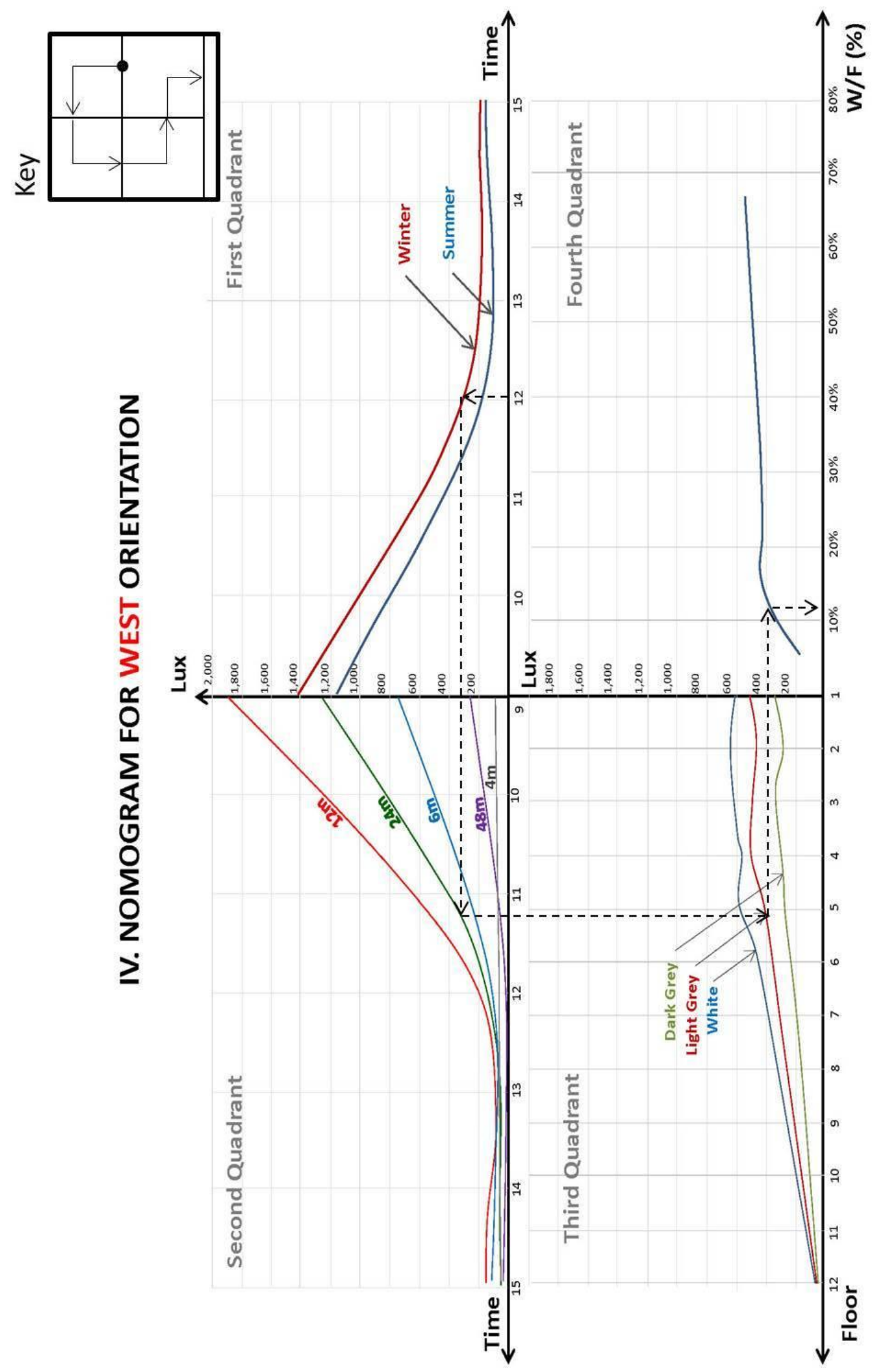



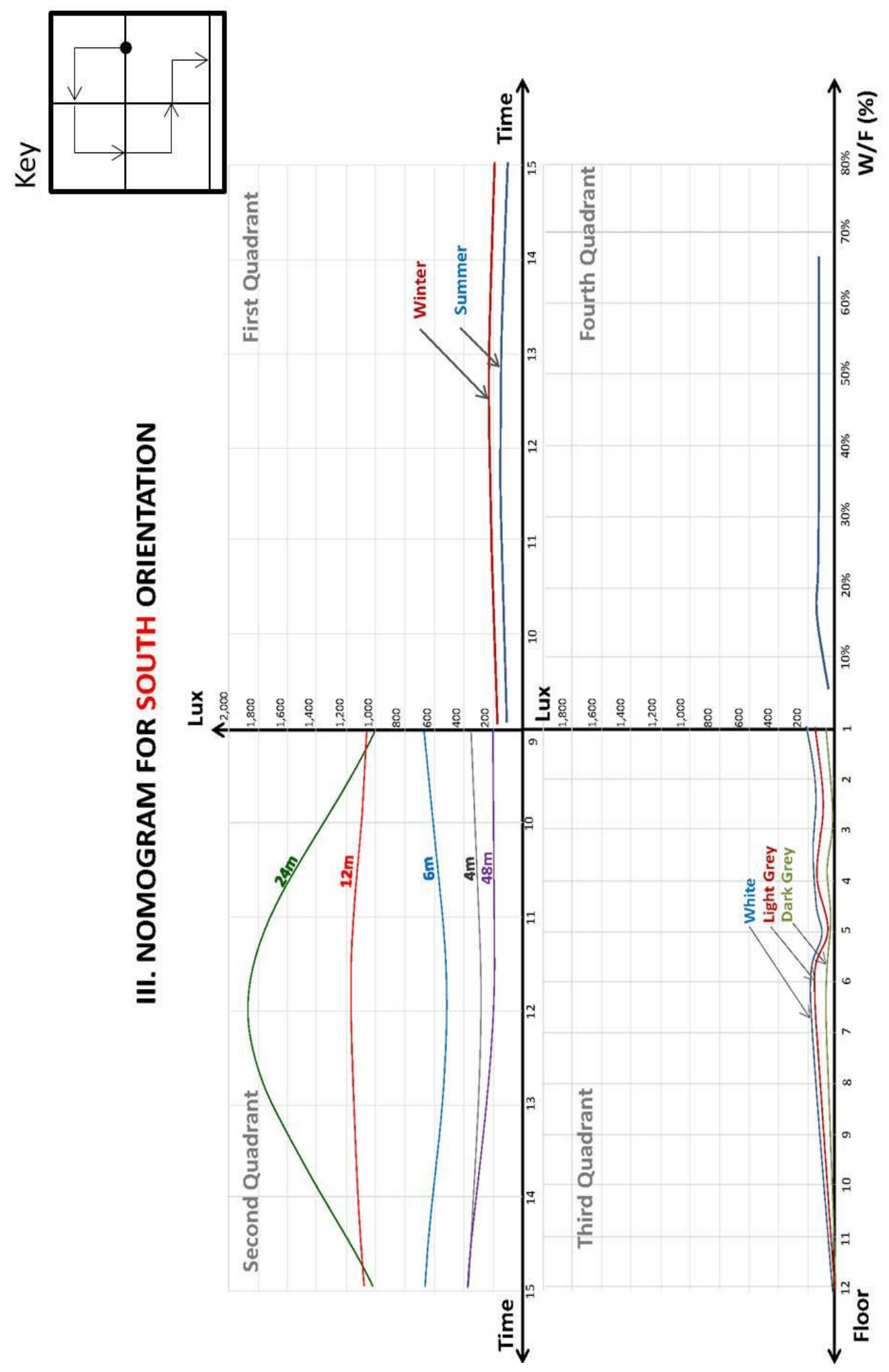

Fig. 18 - South Orientation Nomogram 


\section{RECOMMENDATIONS AND CONCLUSION}

- Designer to use Light façade colors for South Buildings orientation of projects located in Cairo, Egypt to maximize ERC reflectivity, and is required to enhance the daylight value by relying on other components such as IRC.

- Designer can rely primarily on ERC for daylight requirements of the lower floors where natural light access is limited due to the smaller sky angle resulting in a lower $\mathrm{SC}$ value.

- Designer can eliminate the need for occupants to use light colors on interior walls if the façade of the opposite building is of lighter colors at East and West orientations. North and South orientations will have to factor in additional daylight components in order to satisfy standard daylight requirements for general tasks.

- The Nomograms presented through this dissertation are to be used as a guideline for the designer in order to make correct design decisions.

- More research is suggested to link the subject of thermal with ERC daylighting principles.

\section{REFERENCES}

1. Philips, Derek, with Gardner, Carl. "Daylighting, Natural Light in Architecture", Architectural Press, Oxford, 2004.

2. Hofmann, Harald, "Handbook of Lighting Design", ERCO Leuchten, Berlin, 1992.

3. David Egan, M,; "Concepts in Architectural Lighting", McGraw-Hill, 1983

4. Egan, M. David and Olgay, Victor W.; "Architectural Lighting", McGraw-Hill, 2nd edition, 2003.

5. Egyptian Meteorological Authority, Climatological Norms, 1975. 